\title{
The hop phytoestrogen, 8-prenylnaringenin, reverses the ovariectomy- induced rise in skin temperature in an animal model of menopausal hot flushes
}

\author{
James Bowe, Xiao Feng Li, James Kinsey-Jones, Arne Heyerick', Susan Brain², Stuart Milligan \\ and Kevin $\mathbf{O}^{\prime}$ Byrne \\ Division of Reproduction and Endocrinology, King's College London, 2.36D New Hunt's House, Guy's Campus, London SE1 1UL, UK \\ ${ }^{1}$ Laboratory of Pharmacognosy and Phytochemistry, Faculty of Pharmaceutical Sciences, Ghent University, Harelbekestraat 72, B-9000 Ghent, Belgium \\ ${ }^{2}$ Cardiovascular Division, New Hunt's House, King's College London, Guy's Campus, London SE1 1UL, UK \\ (Requests for offprints should be addressed to K O'Byrne; Email: kevin.o'byrne@kcl.ac.uk)
}

\begin{abstract}
The mechanisms underlying menopausal hot flushes are poorly understood, although it is generally assumed they result from disturbances of thermoregulatory centres in the hypothalamus. 8-Prenylnaringenin (8-PN) has been identified as a potent phytoestrogen in hops (Humulus lupulus) and there are claims that hop-containing preparations can reduce hot flushes. We have investigated the site of action of 8-PN in a rat model of menopausal hot flushes, in which the tail skin temperature (TST) is increased after oestrogen withdrawal induced by ovariectomy. Daily s.c. administration of either $17 \beta$-oestradiol $\left(\mathrm{E}_{2} ; 4 \mu \mathrm{g} / \mathrm{kg}\right)$ or 8 -PN $(400 \mu \mathrm{g} / \mathrm{kg})$ significantly reduced the elevated TST after 2 days of treatment. Subcutaneous co-administration of either $\mathrm{E}_{2}$ or 8-PN with
\end{abstract}

the oestrogen receptor (ER) antagonist, ICI 182,780 $(200 \mu \mathrm{g} / \mathrm{kg})$, which is thought not to cross the blood-brain barrier, completely blocked the effect of $\mathrm{E}_{2}$ and 8-PN on TST. The ER $\alpha$ - and ER $\beta$-specific agonists, $4,4^{\prime}, 4^{\prime \prime}$ (4-propyl-[1H]-pyrazole-1,3,5-triyl)trisphenol $(100 \mu \mathrm{g} / \mathrm{kg})$ and 2,3-bis(4-hydroxyphenyl)-propionitrile $(60 \mu \mathrm{g} / \mathrm{kg})$ respectively, both significantly reversed the raised TST in ovariectomised rats. These observations suggest that the regulation of the vasomotor response by oestrogens and phytoestrogens is mediated, at least in part, by peripheral mechanisms involving both ER $\alpha$ and $\operatorname{ER} \beta$.

Journal of Endocrinology (2006) 191, 399-405

\section{Introduction}

Hot flushes are a distressing symptom of the menopausal syndrome, affecting over $75 \%$ of women, many of whom seek medical treatment because their severity greatly impacts on their quality of life (Shanafelt et al. 2002). The pathophysiology of hot flushes is unknown, but $17 \beta$-oestradiol $\left(\mathrm{E}_{2}\right)$ plays a key role because the symptoms are associated with declining levels at menopause or a consequence of $\mathrm{E}_{2}$ deficiency after oophorectomy. Although oestrogen therapy is the mainstay of treatment for this symptom, recent reports highlighting adverse effects, such as breast cancer, stroke and thromboembolism have raised concerns and anxiety amongst both patients and practitioners (Chen et al. 2002, Rossouw 2002, Rossouw et al. 2002).

There has been growing interest in the use of phytoestrogens as 'alternative' therapies for hot flushes. However, limited evidence from small randomised controlled trials provides mixed results suggesting that soy protein and isolated isoflavones do not reduce hot flushes substantially (Shanafelt et al. 2002). A recurring suggestion over the years has been that hops (Humulus lupulus), which have been used for centuries as a preservative and a flavouring agent in beer have powerful oestrogenic activity. When hops were picked by hand, menstrual disturbances amongst women pickers were reportedly common (Verzele 1986). Hop baths have been used for the treatment of gynaecological disorders and hop extracts have been reported to reduce hot flushes in menopausal women (Goetz 1990). A potent oestrogenic compound in hops and beer has been identified as 8-prenylnaringenin (8-PN; Milligan et al. 1999, 2002). Recent studies of this compound have indicated that it may act as a selective oestrogen receptor modulator (SERM) with greater selectivity towards bone compared with the uterus (Hümpel et al. 2005), raising the possibility that it could provide a useful alternative to classic hormone-replacement regimens ( $\operatorname{Rad}$ et al. 2006). This paper reports the effects of 8-PN in a rat model for studying hot flushes (Berendsen et al. 2001, Hosono et al. 2001, Pan et al. 2001, Opas et al. 2004, Sipe et al. 2004). This model uses the rise in tail skin temperature (TST) induced by oestrogen deficiency, with the TST being monitored 
remotely by telemetry. Berendsen et al. (2001) showed that $\mathrm{E}_{2}$, tibolone and clonidine, all reversed the raised TST induced by $\mathrm{E}_{2}$ deficiency. We investigated whether $8-\mathrm{PN}$ could mimic the effect of $\mathrm{E}_{2}$ in reversing the increase in TST induced by ovariectomy, and whether this effect may involve a peripheral site of action mediated by either oestrogen receptor (ER) $\alpha$ or $\operatorname{ER} \beta$.

\section{Materials and Methods}

\section{Animals and surgical procedures}

Adult female Wistar rats, weighing 230-280 g, obtained from Bantin \& Kingman Suppliers, Ltd (Hull, UK) were housed under controlled conditions (12 h light:12 h darkness; lights on at $0700 \mathrm{~h}$; temperature at $22 \pm 2{ }^{\circ} \mathrm{C}$ ) and provided with standard rat diet and water available ad libitum except when indicated otherwise. All animal procedures were undertaken in accordance with the United Kingdom Home Office Regulations. Rats were bilaterally ovariectomised (ovx) and implanted with a temperature and physical activity transmitter (TA10TA-F40, Data Sciences International, St. Paul, MN, USA) under isofluorane anaesthesia (Abbott Animal Health, Queensborough, Kent, UK). The body of the transmitter was implanted subcutaneously (s.c.) in the dorsolateral abdominal region, whilst the tip of the temperature probe was tunnelled s.c. on the dorsal surface of the tail and placed $2 \mathrm{~cm}$ from the fur line at the base of the tail. After implantation, rats were left to recover for 7-10 days prior to commencing studies.

\section{Measurement of tail skin temperature}

Animals were housed individually in cages positioned above a receiver for the telemetric data (RPC-1, Data Sciences International). Cages were separated by thin steel dividers in order to prevent interference between transmitters. Receivers were connected, via a data exchange matrix (Data Sciences International), to a computer in an adjoining room. The Dataquest ART 3.0 program (Data Sciences International) was used to record tail skin temperature from all rats for $7 \mathrm{~s}$ every $5 \mathrm{~min}$. The recording continued $24-\mathrm{h}$ a day throughout the experimental procedure.

\section{Drugs and solutions}

The compounds used in this study were $\mathrm{E}_{2}$ (Sigma-Aldrich), the hop-derived phytoestrogen 8-PN (prepared as described by Possemiers et al. (2005)), the non-selective oestrogen receptor antagonist ICI 182,780 (Tocris Cookson Ltd, Avonmouth, UK), and the selective ER $\alpha$ and ER $\beta$ agonists 4,4', $4^{\prime}$-(4-propyl-[1H]-pyrazole-1,3,5-triyl)trisphenol (PPT) and 2,3-bis(4-hydroxyphenyl)-propionitrile (DPN) respectively (Tocris Cookson Ltd). For s.c. administration, $\mathrm{E}_{2}, 8-\mathrm{PN}$ and ICI 182,780 were initially dissolved in ethanol, and PPT and DPN were dissolved in dimethyl sulphoxide (DMSO). All these were further diluted in arachis oil (Sigma-Aldrich). All the chemicals were injected s.c. in a volume of $1 \mathrm{ml} / \mathrm{kg}$. Control animals were injected with vehicle alone. For oral administration, $\mathrm{E}_{2}$ or 8-PN were dissolved in ethanol, and then mixed into a mash of phytoestrogen-depleted rat chow (Special Diets Services, Witham, Essex, UK).

\section{Subcutaneous administration}

Compounds were evaluated for their ability to decrease TST during the dark period when administered subcutaneously. A 13-day treatment paradigm was used during which TST was monitored continuously. Following an initial pre-test period of 3 days, the compounds were administered for 5 days, followed by a further 5 days of nil treatment. Injections were given s.c. at $1830 \mathrm{~h}, 30 \mathrm{~min}$ prior to lights being turned off. For treatments with ICI $182,780(200 \mu \mathrm{g} / \mathrm{kg}$ per day $)$ in combination with either $\mathrm{E}_{2}(4 \mu \mathrm{g} / \mathrm{kg}$ per day) or $8-\mathrm{PN}$ $(400 \mu \mathrm{g} / \mathrm{kg}$ per day), animals were primed with ICI 182,780 alone for 2 days before the 5-day combined treatment with ICI 182,780 and $E_{2}$ or $8-P N$. In animals given PPT $(1 \mathrm{mg} / \mathrm{kg}$ per day) or DPN (600 $\mu \mathrm{g} / \mathrm{kg}$ per day) subcutaneously, vaginal smears were taken following the final treatment day and stained with $0 \cdot 25 \%$ toluidine blue.

\section{Oral administration}

Both $\mathrm{E}_{2}$ and 8-PN were also evaluated for their ability to decrease TST when given orally in the diet. In preliminary studies, it was calculated that the rats ate, on average, $30 \mathrm{~g}$ diet per day approximately. Therefore, the inclusion of $250 \mu \mathrm{g}$ $\mathrm{E}_{2} / 100 \mathrm{~g}$ diet or $25 \mathrm{mg} 8-\mathrm{PN} / 100 \mathrm{~g}$ diet provided a daily intake of about $75 \mu \mathrm{g} \mathrm{E}$ or $7.5 \mathrm{mg} 8-\mathrm{PN}$. A 16-day treatment paradigm was used during which TST was monitored continuously. For the initial 5 days, animals received phytoestrogen-depleted diet available ad libitum (Special Diets Services). Following this, rats received the phytoestrogen-depleted diet ( $30 \mathrm{~g} /$ day) containing either $\mathrm{E}_{2}$ or $8-\mathrm{PN}$ for 6 consecutive days. For the remaining 5 days, animals received phytoestrogen-depleted diet available ad libitum.

\section{Statistical analysis}

TST data were collected for $7 \mathrm{~s}$ every $5 \mathrm{~min}$ throughout the experimental period. The mean TST during the $12 \mathrm{~h}$ darkness period for each day was calculated and data were analyzed as the change in mean TST $(\Delta T S T)$ on each day compared with the mean TST on day 1. A one-way ANOVA was performed comparing $\triangle \mathrm{TST}$ on each day with the equivalent day in vehicle-treated animals.

\section{Results}

Treatment with $\mathrm{E}_{2}$ at a dose of $4 \mu \mathrm{g} / \mathrm{kg}$ per day (s.c.) resulted in a significant fall in TST in ovx rats by the second day of 
exposure and the TST continued to decrease throughout the period of $E_{2}$ exposure (Fig. 1). After $E_{2}$ administration was stopped, TST took about 4 days to return to baseline levels. Subcutaneous daily administration of $400 \mu \mathrm{g} / \mathrm{kg}$ per day 8 $\mathrm{PN}$ resulted in a decrease in TST similar to that caused by $\mathrm{E}_{2}$ (Fig. 2). TST was significantly lower by the second day of treatment and the TST continued to fall throughout the course of the treatment period. TST recovered to baseline levels about 5 days following the end of treatments (Fig. 2). The oestrogen receptor antagonist ICI 182,780 had no effect on its own (data not shown), but completely blocked the $\mathrm{E}_{2^{-}}$ and 8-PN-induced decrease in TST (Figs 1 and 2 respectively).

To investigate the specific ERs involved in the $\mathrm{E}_{2}$-induced decrease in TST, the specific ER $\alpha$ and ER $\beta$ agonists, PPT $(1 \mathrm{mg} / \mathrm{kg}$, s.c.) and DPN $(0.6 \mathrm{mg} / \mathrm{kg}$, s.c.) respectively were administered. Both PPT and DPN alone significantly lowered TST after 3 days of treatment (Fig. 3). Recovery of TST to baseline values occurred on day 2 following the end of treatment with the selective ER agonists (Fig. 3). To confirm receptor specificity, vaginal smears were examined. In rats treated with PPT (ER $\alpha$ agonist) vaginal smears had abundant cornified cells, whilst rats treated with DPN (ER $\beta$ agonist) showed no evidence of vaginal cornification.

Both $\mathrm{E}_{2}(75 \mu \mathrm{g} /$ day $)$ and $8-\mathrm{PN}(7.5 \mathrm{mg} /$ day $)$ also significantly lowered TST when administered orally in the diet. Oral $\mathrm{E}_{2}$ significantly reduced TST by the second day of treatment, whilst oral 8-PN significantly reduced TST following 3 days of treatment (Fig. 4). Following oral administration of either $\mathrm{E}_{2}$ or 8-PN TST values returned to baseline levels 2 days after the end of treatment (Fig. 4). Additionally, it should be noted that rats maintained on the phytoestrogen-depleted rat diet used in oral administration

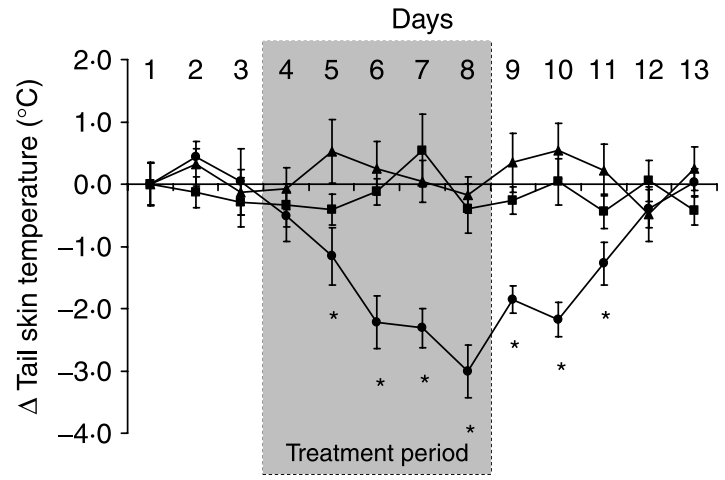

Figure 1 Effects of s.c. administration of $17 \beta$-oestradiol $\left(E_{2}\right.$; 0; $4 \mu \mathrm{g} / \mathrm{kg}$ per day), $\mathrm{E}_{2}$ and $\mathrm{ICI} 182,780(\boldsymbol{\Delta} ; 4 \mu \mathrm{g} / \mathrm{kg}$ per day and $200 \mu \mathrm{g} / \mathrm{kg}$ per day respectively) or peanut oil ( $; 1 \mathrm{ml} / \mathrm{kg}$ ) on tail skin temperature (TST) in the ovariectomised rat. Shaded area from days 4 to 8 indicates period during which treatment was given. Shown are the mean changes in TST ( \pm S.E.M.) compared with the mean values on day $1(\Delta \mathrm{TST})$. Temperature measurements were taken from the dark period (1900-0700 h) of telemetric monitoring. Administration of the ICI 182,780 completely blocked the effect of $\mathrm{E}_{2} .{ }^{*} P<0 \cdot 05$ vs vehicle control on same day. $n=7-9$.

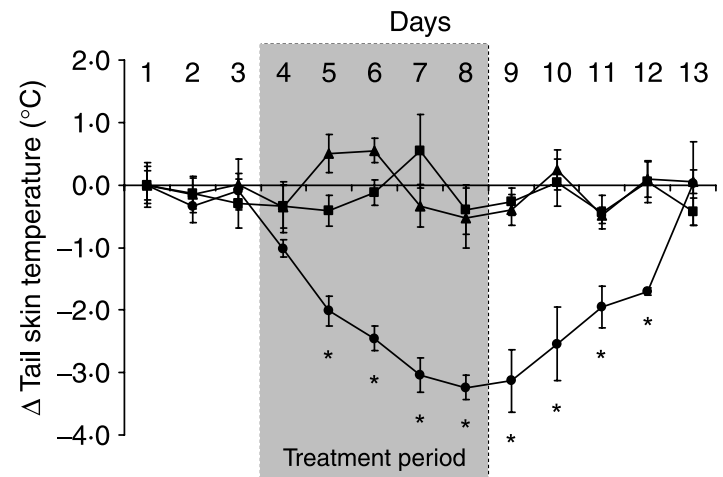

Figure 2 Effects of s.c. administration of 8-prenylnaringenin (8-PN; ; $400 \mu \mathrm{g} / \mathrm{kg}$ per day), 8-PN and ICI 182,780 ( $\mathbf{\Delta} ; 400 \mu \mathrm{g} / \mathrm{kg}$ per day and $200 \mu \mathrm{g} / \mathrm{kg}$ per day respectively) or peanut oil $(\boldsymbol{\square} ; 1 \mathrm{ml} / \mathrm{kg})$ on tail skin temperature (TST) in the ovariectomised rat. Shaded area from days 4 to 8 indicates period during which treatment was given. Shown are the mean changes in TST $( \pm$ S.E.M. $)$ compared with the mean values on day 1 ( $\Delta$ TST). Temperature measurements were taken from the dark period (1900-0700 h) of telemetric monitoring. Administration of $\mathrm{ICI} 182,780$ completely blocked the effect of 8PN. ${ }^{*} P<0 \cdot 05$ vs vehicle control on the same day. $n=7$.

studies had significantly higher baseline TST measurements than those maintained on the standard rat diet used for s.c. administration studies $\left(29 \cdot 34 \pm 0 \cdot 17\right.$ vs $31 \cdot 23 \pm 0 \cdot 23{ }^{\circ} \mathrm{C}$ in animals fed standard rat diet compared with phytoestrogendepleted rat diet respectively; $P<0 \cdot 05)$.

\section{Discussion}

Our data show that the hop-derived phytoestrogen, 8-PN, is capable of reducing the raised skin temperatures occurring in a rat model of menopausal hot flushes, when administered

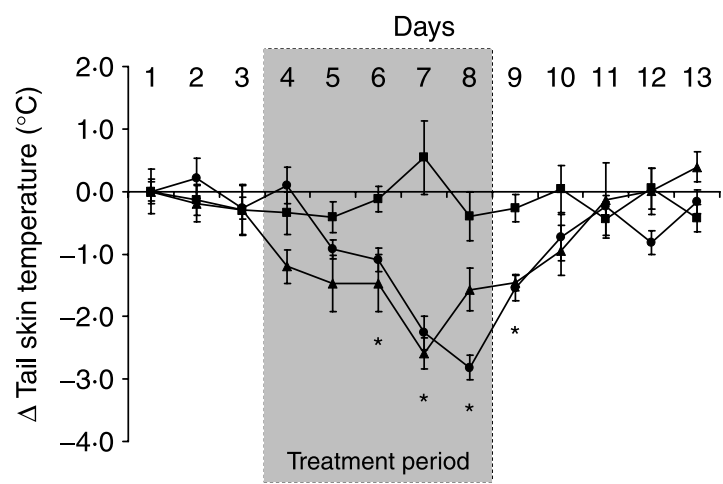

Figure 3 Effects of s.c. administration of the selective ER $\alpha$ agonist, PPT $(\bullet ; 1 \mathrm{mg} / \mathrm{kg}$ per day), the selective ER $\beta$ agonist, DPN

$(\boldsymbol{\Delta} ; 600 \mu \mathrm{g} / \mathrm{kg}$ per day) or peanut oil $(\boldsymbol{\square} ; 1 \mathrm{ml} / \mathrm{kg})$ on tail skin temperature (TST) in the ovariectomised rat. Shaded area from days 4 to 8 indicates period during which treatment was given. Shown are the mean changes in TST $( \pm$ s.E.M.) compared with the mean values on day 1 ( $\Delta$ TST). Temperature measurements were taken from the dark period (1900-0700 h) of telemetric monitoring. ${ }^{*} P<0 \cdot 05$ vs vehicle control on the same day. $n=7$. 


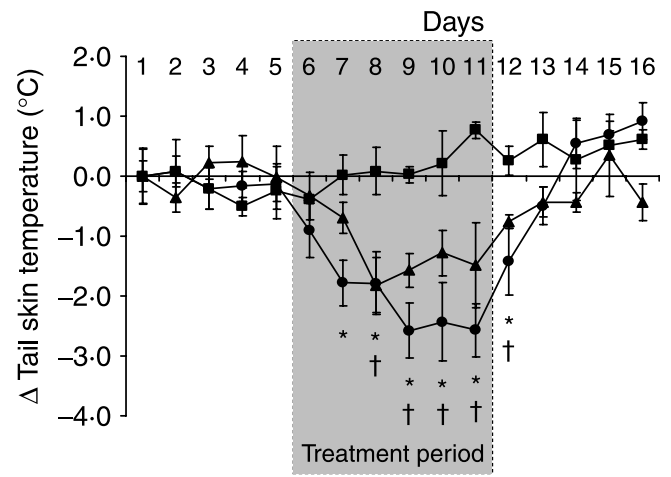

Figure 4 Effects of oral administration of $17 \beta$-oestradiol $\left(E_{2}\right.$; ; $75 \mu \mathrm{g} /$ day) or 8-prenylnaringenin (8-PN; $\mathbf{\Delta}$; $7.5 \mathrm{mg} /$ day) on tail skin temperature (TST) in the ovariectomised rat. Control animals were fed phytoestrogen-depleted rat diet ( $\boldsymbol{\square})$ Shaded area from days 6 to 11 indicates period during which treatment was given. Shown are the mean changes in TST ( \pm S.E.M.) compared with the mean values on day $1(\Delta \mathrm{TST})$. Temperature measurements were taken from the dark period (1900-0700 h) of telemetric monitoring. ${ }^{*} P<0.05 \mathrm{E}_{2}$ vs vehicle control on the same day. ${ }^{\dagger} P<0 \cdot 058$-PN vs vehicle control on the same day. $n=4-5$.

either subcutaneously or orally. Soy isoflavones present in the diet have also been shown to suppress the increased TST resulting from ovariectomy (Pan et al. 2001, Opas et al. 2004), although the effects were more modest than those observed in the present study. The reduction of TST caused by s.c. administration of both 8-PN and $\mathrm{E}_{2}$ was blocked by ICI 182,780 , a non-selective oestrogen receptor antagonist. These results all confirm the oestrogen sensitivity of the nocturnal elevation of rat tail temperature.

The dose of 8-PN used in the present study (approximately 100 times that of $E_{2}$ ) was based on previous observations of the in vitro and in vivo bioactivities of 8-PN compared with $\mathrm{E}_{2}$ (Milligan et al. 1999, 2002), and this produced a decrease in TST similar in both time-course and degree to that resulting from $\mathrm{E}_{2}$ treatment. The dose of 8-PN used was probably at the lower end of the effective uterotrophic range and Wuttke and colleagues (Christoffel et al. 2006) have recently shown that a comparable dose of this phytoestrogen $(6.8 \mathrm{mg} / \mathrm{kg}$ per day vs $7.5 \mathrm{mg} / \mathrm{kg}$ per day for the present study) had no effect on uterine weight. However, in view of the observations by Hümpel et al. (2005) showing a greater sensitivity of bone to 8-PN compared with uterus, additional dose-response studies comparing the sensitivities of thermoregulatory responses and uterotrophic responses are required to characterise any SERM-like activity.

Hot flushes in women are generally regarded as a thermoregulatory phenomenon with the characteristic peripheral vasodilatation and increased sweating being consistent with a heat dissipation response. The majority of hot flushes are indeed, preceded by an increase in core temperature (Freedman \& Krell 1999) and their incidence increases in a warm environment (Molnar 1981, Kronenberg et al. 1993) or following heating or exercise (Sturdee et al.
1978, Freedman \& Krell 1999). It has been hypothesised that this thermoregulatory response is due to a dramatically reduced thermoregulatory neutral zone (Freedman \& Krell 1999) meaning that even a very small increase in core temperature may cross the temperature threshold for a heat dissipation response. This thermoregulatory nature of hot flushes has led to the assumption that they are generated in the thermoregulatory areas of the anterior hypothalamus as this area contains neurones that monitor and regulate body temperature. However, although the central thermoregulatory regions of the brain are likely to be involved, the aetiology of hot flushes is still relatively unclear. Investigations into the role of oestrogen withdrawal in hot flushes have generally assumed it to be a central effect, but this is without any direct experimental evidence.

Whilst mechanisms within the thermoregulatory centres of the CNS are still likely to be involved, our results indicate the aetiology may well be more complex than a purely central phenomenon and involve peripheral actions of oestrogen. There is considerable evidence to support the idea that the anti-oestrogenic effects of ICI 182,780 after systemic administration are limited to the periphery (Howell et al. 2000). Wade and colleagues showed that peripheral administration of ICI 182,780 blocked the uptake of tritiated oestradiol in the uterus and pituitary, but not in the hypothalamus-preoptic area in the rat (Wade et al. 1993). Tamoxifen, which crosses the blood-brain barrier, inhibits lordosis behaviour in rats treated with oestradiol and progesterone (Patisaul et al. 2004), but lordosis continues after treatment with ICI 182,780 (Clark et al. 2004). Similarly, the hypothalamic expression of progesterone receptors, an $\mathrm{E}_{2}$-dependent brain process is affected by tamoxifen but not by ICI 182,780 (Yin et al. 2002). From a neuroendocrine perspective, $\mathrm{E}_{2}$ control of gonadotrophin secretion is complex, involving both hypothalamic and pituitary sites of action and there are conflicting data regarding the influence of ICI 182,780 on gonadotrophin secretion in human and animal studies. Treatment with ICI 182,780 is a form of pharmacological castration; however, although some studies have described the predicted increase in gonadotrophins (Donath \& Nishino 1998, Ördög et al. 1998), others have observed either no effect (Wakeling et al. 1991, DeFriend et al. 1994) or a suppression of gonadotrophin release in response to ICI 182,780 (Sanchez-Criado et al. 2002). Furthermore, there are presently no definitive studies involving simultaneous measurement of gonadotrophinreleasing hormone $(\mathrm{GnRH})$ in pituitary portal blood and luteinizing hormone $(\mathrm{LH})$ in the peripheral circulation making it difficult to differentiate conclusively the site at which ICI 182,780 is acting. However, Knobil and colleagues have elegantly shown that ICI 182,780 completely blocked the inhibitory action of $\mathrm{E}_{2}$ on GnRH induced LH secretion at the pituitary gland, but did not block the inhibitory action of the steroid on the electrophysiological correlates of the GnRH pulse generator in the brain (Ördög et al. 1998) suggesting an exclusively peripheral effect. Taken together, 
these studies provide strong evidence supporting the postulate that the effects of systemically administered ICI 182,780 are mainly peripheral and that the compound may not cross the blood-brain barrier. Therefore, its effect in blocking the action of oestrogens on tail skin temperature suggests that this effect of oestrogen may reflect a significant peripheral component. However, this discussion must be treated with some caution as the blood-brain barrier is not a fixed entity and indeed can be affected by oestrogenic status. $\mathrm{E}_{2}$ promotes blood-brain barrier integrity in young adult female rats (Bake \& Sohrabji 2004, Chi et al. 2004), and the permeability of the barrier is increased in reproductive senescent females rats and this is further exacerbated by $\mathrm{E}_{2}$ (Bake \& Sohrabji 2004). Therefore, the possibility that the action of ICI 182,780 to block the effects of $\mathrm{E}_{2}$ and 8 -PN on vasomotor responses may be modified with age should be considered.

The majority of phytoestrogens, including coumestrol and genistein, have a stronger binding affinity for ER $\beta$ than for ER $\alpha$ (Kuiper \& Gustafsson 1997, Casanova et al. 1999, Overk et al. 2005), although 8-PN shows little difference in the binding affinity for the two receptors (Milligan et al. 2002) or has a higher affinity for ER $\alpha$ (Schaefer et al. 2003, Overk et al. 2005). The fact that both the selective ER $\alpha$ and ER $\beta$ agonists, PPT and DPN (Meyers et al. 2001, Sanchez-Criado et al. 2004) reversed the raised TST response suggests the pathways mediating the oestrogenic effects may involve both receptors. The reduction of TST in the ovx rat in response to PPT confirms previously published results implicating a role for $E R \alpha$ (Harris et al. 2002), whilst the data showing an equivalent decrease in response to DPN administration (at the same molar dosage) indicates an equally important role for ER $\beta$ in the oestrogenic modulation of this vasomotor response. Indeed, it has recently been shown in ER knockout mice that expression of either $\operatorname{ER} \alpha$ or $\operatorname{ER} \beta$ alone can control TST by oestrogen (Opas et al. 2006). In the present study, the specificity of the ER agonists was confirmed by the fact that the ER $\alpha$ agonist PPT, but not the ER $\beta$ agonist DPN, resulted in the development of cornified vaginal smears during treatment, as shown previously (Sanchez-Criado et al. 2004). ER $\alpha$ and $E R \beta$ are differentially expressed in tissues, including the vasculature. The tail artery, which is directly responsible for TST regulation, contains predominantly ER $\beta$ with relatively low levels of $\mathrm{ER} \alpha$ (Orimo et al. 1993, Andersson et al. 2001), whilst other vessels, such as the uterine artery and aorta contain significantly higher levels of ER $\alpha$ compared with ER $\beta$ (Andersson et al. 2001). Given such differential distribution of oestrogen receptors, it is possible that $\operatorname{ER} \alpha$ and $E R \beta$ may have different roles in the oestrogenic suppression of raised TST.

The effectiveness of 8-PN in alleviating the raised TST in ovx rats is consistent with the reported ability of hops or hop extracts to exert oestrogenic effects in women and the hypothesis that 8-PN might prove effective in treating menopausal hot flushes. In particular, the effectiveness of orally administered 8-PN in lowering TST in an animal model for the study of menopausal hot flushes is encouraging, since it is preferable for treatments of clinical interest to be active when given orally. Rad et al. (2006) have recently shown that single oral doses of up to $750 \mathrm{mg}$ 8-PN are well tolerated by postmenopausal women, and that the compound is rapidly absorbed, has high metabolic stability and is associated with pronounced enterohepatic recirculation. When hops were hand-picked menstrual disturbances amongst women hop pickers were common and hop baths have been used in the past for the treatment of gynaecological disorders (Verzele 1986). There is also a report of hop extracts being effective in treating hot flushes in menopausal women (Goetz 1990). Hops contain a number of different phytoestrogens, the most potent of which is 8-PN (Milligan et al. 1999). Hops also contain considerable amounts of the non-oestrogenic isoxanthohumol, which can readily be converted to 8 -PN by intestinal microbes (Possemiers et al. 2005). Whilst there is still great interest in their potential as an alternative therapy for menopausal hot flushes, numerous clinical trials have failed to prove that administration of soy phytoestrogens has a significant effect on menopausal symptoms compared with placebo treatments (Ososki \& Kennelly 2003, Krebs et al. 2004). However, it has recently been shown that a hop extract, standardised on 8-PN, exerted favourable effects on vasomotor symptoms and other menopausal discomforts (Heyerick et al., 2006). The present study showing the ability of 8-PN to reverse the thermoregulatory disturbances in ovariectomised rats, together with the encouraging clinical reports that $8-\mathrm{PN}$ is effective in alleviating menopausal symptoms, suggests that further studies of $8-\mathrm{PN}$ as a potential alternative therapy to hormone replacement therapy are warranted.

\section{Acknowledgements}

We would also like to thank $\mathrm{H}$ Berendsen and colleagues, Organon, Oss, Netherlands for their technical advice in setting up the telemetry system.

\section{Funding}

This work was supported by the Guy's and St Thomas' Charitable Foundation, UK and The Wellcome Trust. JB is a recipient of the Guy's and St Thomas' Charitable Foundation (UK) PhD Studentship. The sources of funding provide no conflict of interest that would affect this study's impartiality.

\section{References}

Andersson C, Lydrup ML, Ferno M, Idvall I, Gustafsson J \& Nilsson BO 2001 Immunocytochemical demonstration of oestrogen receptor beta in blood vessels of the female rat. Journal of Endocrinology 169 241-247.

Bake S \& Sohrabji F 2004 17beta-estradiol differentially regulates blood-brain barrier permeability in young and aging female rats. Endocrinology 145 $5471-5475$. 
Berendsen HH, Weekers AH \& Kloosterboer HJ 2001 Effect of tibolone and raloxifene on the tail temperature of oestrogen-deficient rats. European Journal of Pharmacology 419 47-54.

Casanova M, You L, Gaido KW, Archibeque-Engle S, Janszen DB \& Heck HA 1999 Developmental effects of dietary phytoestrogens in Sprague-Dawley rats and interactions of genistein and daidzein with rat estrogen receptors alpha and beta in vitro. Toxicological Sciences 51 236-244.

Chen CL, Weiss NS, Newcomb P, Barlow W \& White E 2002 Hormone replacement therapy in relation to breast cancer. Journal of the American Medical Association 287 734-741.

Chi OZ, Barsoum S, Wen Y, Liu X \& Weiss HR 2004 17beta-estradiol prevents blood-brain barrier disruption induced by VEGF. Hormone and Metabolic Research 36 272-276.

Christoffel J, Rimoldi G \& Wuttke W 2006 Effects of 8-prenylnaringenin on the hypothalamo-pituitary-uterine axis in rats after 3-month treatment. Journal of Endocrinology 188 397-405.

Clark AS, Guarraci FA, Megroz AB, Porter DM \& Henderson LP 2004 The display of sexual behaviors by female rats administered ICI 182,780. Hormones and Behavior 43 454-464.

DeFriend DJ, Howell A, Nicholson RI, Anderson E, Dowsett M, Mansel RE, Blamey RW, Bundred NJ, Robertson JF \& Saunders C 1994 Investigation of a new pure antiestrogen (ICI 182780) in women with primary breast cancer. Cancer Research 54 408-414.

Donath J \& Nishino Y 1998 Effects of partial versus pure antiestrogens on ovulation and the pituitary-ovarian axis in the rat. Journal of Steroid Biochemistry and Molecular Biology 66 247-254.

Freedman RR \& Krell W 1999 Reduced thermoregulatory null zone in postmenopausal women with hot flashes. American Journal of Obstetrics and Gynecology 181 66-70.

Goetz P 1990 Treatment of hot flashes due to ovarian insufficiency using a hops extract (Humulus lupus). Revue de Phytotherapie Pratique 4 13-15.

Harris HA, Katzenellenbogen JA \& Katzenellenbogen BS 2002 Characterization of the biological roles of the estrogen receptors, ERalpha and ERbeta, in estrogen target tissues in vivo through the use of an ERalphaselective ligand. Endocrinology 143 4172-4177.

Heyerick A, Vervarcke S, Depypere H, Bracke M \& Keukeleire DD 2006 A first prospective, randomized, double-blind, placebo-controlled study on the use of a standardized hop extract to alleviate menopausal discomforts. Maturitas 54 164-175.

Hosono T, Chen XM, Miyatsuji A, Yoda T, Yoshida K, Yanase-Fujiwara M \& Kanosue K 2001 Effects of estrogen on thermoregulatory tail vasomotion and heat-escape behavior in freely moving female rats. American Journal of Physiology 280 R1341-R1347.

Howell A, Osborne CK, Morris C \& Wakeling AE 2000 ICI 182,780 (Faslodex): development of a novel, 'pure' antiestrogen. Cancer 89 817-825.

Hümpel M, Isaksson P, Schaefer O, Kaufmann U, Ciana P, Maggi A \& Schleuning WD 2005 Tissue specificity of 8-prenylnaringenin: protection from ovariectomy induced bone loss with minimal trophic effects on the uterus. Journal of Steroid Biochemistry and Molecular Biology 97 299-305.

Krebs EE, Ensrud KE, MacDonald R \& Wilt TJ 2004 Phytoestrogens for treatment of menopausal symptoms: a systematic review. Obstetrics and Gynecology 104 824-836.

Kronenberg F, Mallory B \& Downey JA 1993 Women's health: new frontiers in rehabilitation medicine. Archives of Physical Medicine and Rehabilitation $\mathbf{7 4}$ 1377-1378.

Kuiper GG \& Gustafsson JA 1997 The novel estrogen receptor-beta subtype: potential role in the cell- and promoter-specific actions of estrogens and anti-estrogens. Federation of European Biochemical Societies Letters 410 87-90.

Meyers MJ, Sun J, Carlson KE, Marriner GA, Katzenellenbogen BS \& Katzenellenbogen JA 2001 Estrogen receptor-beta potency-selective ligands: structure-activity relationship studies of diarylpropionitriles and their acetylene and polar analogues. Journal of Medicinal Chemistry $4 \mathbf{4}$ 4230-4251.

Milligan SR, Kalita JC, Heyerick A, Rong H, De CL \& De KD 1999 Identification of a potent phytoestrogen in hops (Humulus lupulus L.) and beer. Journal of Clinical Endocrinology and Metabolism 84 2249-2252.
Milligan SR, Kalita J, Pocock V, Heyerick A, De CL, Rong H \& De KD 2002 Oestrogenic activity of the hop phyto-oestrogen, 8-prenylnaringenin. Reproduction 123 235-242.

Molnar GW 1981 Menopausal hot flashes: their cycles and relation to air temperature. Obstetrics and Gynecology 57 52S-55S.

Opas EE, Rutledge SJ, Vogel RL, Rodan GA \& Schmidt A 2004 Rat tail skin temperature regulation by estrogen, phytoestrogens and tamoxifen. Maturitas 48 463-471.

Opas EE, Gentile MA, Kimmel DB, Rodan GA \& Schmidt A 2006 Estrogenic control of thermoregulation in ERalphaKO and ERbetaKO mice. Maturitas 53 210-621.

Ördög T, Goldsmith JR, Chen MD, Connaughton MA, Hotchkiss J \& Knobil E 1998 On the mechanism of the positive feedback action of estradiol on luteinizing hormone secretion in the rhesus monkey. Journal of Clinical Endocrinology and Metabolism 83 4047-4053.

Orimo A, Inoue S, Ikegami A, Hosoi T, Akishita M, Ouchi Y, Muramatsu M \& Orimo H 1993 Vascular smooth muscle cells as target for estrogen. Biochemical and Biophysical Research Communications 195 730-736.

Ososki AL \& Kennelly EJ 2003 Phytoestrogens: a review of the present state of research. Phytotherapy Research 17 845-869.

Overk CR, Yao P, Chadwick LR, Nikolic D, Sun Y, Cuendet MA, Deng Y, Hedayat AS, Pauli GF, Farnsworth NR et al. 2005 Comparison of the in vitro estrogenic activities of compounds from hops (Humulus lupulus) and red clover (Trifolium pratense). Journal of Agricultural and Food Chemistry $\mathbf{5 3}$ 6246-6253.

Pan Y, Anthony MS, Binns M \& Clarkson TB 2001 A comparison of oral micronized estradiol with soy phytoestrogen effects on tail skin temperatures of ovariectomized rats. Menopause 8 171-174.

Patisaul HB, Luskin JR \& Wilson ME 2004 A soy supplement and tamoxifen inhibit sexual behavior in female rats. Hormones and Behavior 45 270-277.

Possemiers S, Heyerick A, Robbens V, De KD \& Verstraete W 2005 Activation of proestrogens from hops (Humulus lupulus L.) by intestinal microbiota; conversion of isoxanthohumol into 8-prenylnaringenin. Journal of Agricultural and Food Chemistry 53 6281-6288.

Rad M, Hümpel M, Schaefer O, Schoemaker RC, Schleuning W-D, Cohen AF \& Burggraaf J 2006 Pharmacokinetics and systemic endocrine effects of the phyto-oestrogen 8-prenylnaringenin after single oral doses to postmenopausal women. British Journal of Clinical Pharmacology 62 288-296.

Rossouw JE 2002 Effect of postmenopausal hormone therapy on cardiovascular risk. Journal of Hypertension. Supplement 20 S62-S65.

Rossouw JE, Anderson GL, Prentice RL, LaCroix AZ, Kooperberg C, Stefanick ML, Jackson RD, Beresford SA, Howard BV, Johnson KC et al. 2002 Risks and benefits of estrogen plus progestin in healthy postmenopausal women: principal results from the Women's Health Initiative randomized controlled trial. Journal of the American Medical Association 288 321-333.

Sanchez-Criado JE, Guelmes P, Bellido C, Gonzalez M, Hernandez G, Aguilar R, Garrido-Gracia JC, Bello AR \& Alonso R 2002 Tamoxifen but not other selective estrogen receptor modulators antagonises estrogen actions on luteinizing hormone secretion while inducing gonadotropinreleasing hormone self-priming in the rat. Neuroendocrinology $\mathbf{7 6}$ 203-213.

Sanchez-Criado JE, Martin De Las MJ, Bellido C, Tena-Sempere M, Aguilar R \& Blanco A 2004 Biological role of pituitary estrogen receptors ERalpha and ER beta on progesterone receptor expression and action and on gonadotropin and prolactin secretion in the rat. Neuroendocrinology 79 247-258.

Schaefer O, Humpel M, Fritzemeier KH, Bohlmann R \& Schleuning WD 2003 8-Prenyl naringenin is a potent ERalpha selective phytoestrogen present in hops and beer. Journal of Steroid Biochemistry and Molecular Biology 84 359-360.

Shanafelt TD, Barton DL, Adjei AA \& Loprinzi CL 2002 Pathophysiology and treatment of hot flashes. Mayo Clinic Proceedings 77 1207-1218.

Sipe K, Leventhal L, Burroughs K, Cosmi S, Johnston GH \& Deecher DC 2004 Serotonin 2A receptors modulate tail-skin temperature in two rodent models of estrogen deficiency-related thermoregulatory dysfunction. Brain Research 1028 191-202.

Sturdee DW, Wilson KA, Pipili E \& Crocker AD 1978 Physiological aspects of menopausal hot flush. British Medical Journal 2 79-80. 
Verzele M 1986100 Years of hop chemistry and its relevance to brewing. Journal of the Institute of Brewing 92 32-48.

Wade GN, Blaustein JD, Gray JM \& Meredith JM 1993 ICI 182,780: a pure antiestrogen that affects behaviors and energy balance in rats without acting in the brain. American Journal of Physiology 265 R1392-R1398.

Wakeling AE, Dukes M \& Bowler J 1991 A potent specific pure antiestrogen with clinical potential. Cancer Research 51 3867-3873.
Yin P, Kawashima K \& Arita J 2002 Direct actions of estradiol on the anterior pituitary gland are required for hypothalamus-dependent lactotrope proliferation and secretory surges of luteinizing hormone but not of prolactin in female rats. Neuroendocrinology 75 392-401.

Received in final form 8 August 2006 Accepted 11 August 2006 